WIDER Working Paper 2016/35

\title{
A review of consumption poverty estimation for Mozambique
}

Channing Arndt, ${ }^{1}$ Sam Jones, ${ }^{2}$ Kristi Mahrt, ${ }^{3}$ Vincenzo Salvucci, ${ }^{1}$ and Finn Tarp ${ }^{1,2}$

April 2016 
Abstract: We broadly review the challenges encountered and choices made in the national assessments of consumption poverty using the 1996/97, 2002/03, and 2008/09 budget surveys. Efforts to maintain consistency with the previous survey imply that prior choices tend to be adopted in subsequent analyses. However, because 'best practice' evolves, there arises a natural tension between the desire to follow best practice and the desire to maintain consistency with previous analyses. New estimates produce qualitatively very similar results. We conclude that the principal conclusions of the poverty assessments are robust. The results also highlight the value of a consistent and reproducible approach.

Keywords: consumption poverty measurement, consistency, Mozambique JEL classification: D63, I32, O55

\footnotetext{
${ }^{1}$ UNU-WIDER, Helsinki, Finland; corresponding author: channing@wider.unu.edu; 2 University of Copenhagen, Denmark; ${ }^{3}$ Independent contractor, Fort Collins, CO, US.

This study has been prepared within the project on 'Inclusive Growth in Mozambique-Scaling-up Research and Capacity' implemented in collaboration between UNU-WIDER, University of Copenhagen, University Eduardo Mondlane, and the Mozambican Ministry of Economics and Finance. The project is financed through specific programme contributions by the governments of Denmark, Finland, Norway, and Switzerland.
}

Copyright (C) UNU-WIDER 2016

Information and requests: publications@wider.unu.edu

ISSN 1798-7237 ISBN 978-92-9256-078-2

Typescript prepared by Leslie O’Brien.

The United Nations University World Institute for Development Economics Research provides economic analysis and policy advice with the aim of promoting sustainable and equitable development. The Institute began operations in 1985 in Helsinki, Finland, as the first research and training centre of the United Nations University. Today it is a unique blend of think tank, research institute, and UN agency_providing a range of services from policy advice to governments as well as freely available original research.

Katajanokanlaituri 6 B, 00160 Helsinki, Finland

The views expressed in this paper are those of the author(s), and do not necessarily reflect the views of the Institute or the United Nations University, nor the programme/project donors. 
Since the end of the civil war in 1992, Mozambique has registered significant progress across a range of monetary and non-monetary poverty indicators at both national and regional levels. This conclusion of material progress draws from a large array of nationally representative data sets that became available starting from 1996. A detailed discussion of the evolution of welfare conditions in Mozambique can be found in Arndt et al. (2016d).

Here, we are concerned with the estimation of consumption poverty rates. Four national household budget surveys have been carried out in Mozambique: 1996/97, 2002/03, 2008/09, and 2014/15. The most recent survey has yet to be analysed as of this writing. Official poverty estimates were computed in a series of national poverty assessments (MPF/DNPO 1998, 2004; MPD/DNEAP 2010). Main results from these analyses indicate that consumption poverty (as measured by the headcount rate) fell significantly from 1996/97 to 2002/03 at the national level, whereas more recent data from 2008/09 show that consumption poverty was essentially the same as in 2002/03 at the national level.

This paper begins by broadly reviewing the challenges encountered and choices made in the national assessments. Efforts to maintain consistency with the previous survey imply that prior choices tend to be adopted in subsequent analyses. At the same time, the practice of consumption poverty analysis is not static. Because 'best practice' evolves (and hopefully improves) with time, there arises a natural tension between the desire to follow best practice and the desire to maintain consistency with previous analyses. In Section 3, we present new consumption poverty estimates for 2002/03 and 2008/09 using the default PLEASe software stream. ${ }^{1}$ Principal differences between the PLEASe software and the methodologies employed in the national assessments are discussed.

A final section discusses in more detail the gradual accretion of tensions between consistency with previous analyses and evolving practice in both data collection and analysis and concludes that the major findings from the three national assessments are robust. The results also point to the strong benefits of applying consistent methods over time implying a need to re-estimate existing results as data collection methods, circumstances, and analytical techniques evolve.

\section{Challenges and choices}

When the civil war finally ended in 1992, Mozambique was labelled the "poorest country in the world' (Arndt et al. 2000). Remarkably, the 1996/97 household consumption survey (IAF96) was in the field only four years later. Not surprisingly, the survey that underpinned Mozambique's first national poverty assessment faced considerable challenges. Challenges encountered in the field included but were not limited to:

1. Degraded or absent infrastructure as a consequence of more than 10 years of civil war;

2. Widespread prevalence of landmines that demanded care while travelling in rural areas;

3. Major flooding in Sofala province that disrupted data collection;

\footnotetext{
${ }^{1}$ We do not pretend to label the default PLEASe as best practice, and certainly not in every case. Nevertheless, the defaults are certainly not manifestly inappropriate for Mozambique and serve as a convenient reference point. Also, as will be discussed, the complete code stream is only applied to the 2002/03 and 2008/09 data.
} 
4. A vast array of non-standard units, which varied drastically across space and significantly complicated the estimation of quantities; and

5. The lack of a census sample frame.

Despite these barriers, a sample was obtained (largely relying on electoral lists from the 1994 election) and more than 8,000 households were interviewed. The questionnaire contained a detailed consumption module alongside a series of other modules, including a community questionnaire. These modules gathered, among other items, market price information, and anthropometrics for children under five years of age. The resulting report was comprehensive and set a high standard for consumption poverty analysis in a low-income context given the knowledge base at the time.

The first assessment adopted a 'cost of basic needs' approach (Ravallion 2016). Analysis of consumption patterns and food prices revealed pronounced differences across regions as well as between rural and urban zones. In a choice that was novel for the time period, the team charged with the first assessment elected to develop separate consumption bundles by region in order to accommodate this variation in consumption patterns and prices. Thirteen spatial domains were identified, of which six were rural and seven urban. ${ }^{2}$

The team conducting the analysis of the 1996/97 survey was well aware of the ongoing debates relating to consistency versus specificity (see Ravallion 2016 for a recent discussion). The team was also large and diverse containing economists as well as specialists in nutrition and agriculture. Substantial efforts were made to arrive at bundles for the 13 spatial domains that provided a similar level of welfare. This occurred through a series of ad hoc adjustments to the bundles underlying the poverty lines. Revealed preference conditions were not evaluated or imposed in the development of the official poverty rates.

As shown in Table 1, the first assessment estimated quite high consumption poverty rates almost everywhere with more than 69 per cent of the population failing to consume more than the very basic standard of living implied by the poverty lines. As one might expect, significant shares of the population clustered near the poverty line. For example, while the estimated rural poverty rate at the full poverty line amounted to more than 71 per cent of the population, the rural population living below the food poverty line (which sits at about 80 per cent of the full poverty line) amounted to 56 per cent of the population.

\footnotetext{
2 There are separate domains for the rural and urban zones of Niassa and Cabo Delgado; Nampula, Sofala, and Zambezia; Manica and Tete; Gaza and Inhambane; Maputo Province plus Maputo City is a final separate domain.
} 
Table 1: Comparison of official and PLEASe poverty estimates.

\begin{tabular}{|c|c|c|c|c|c|c|}
\hline & \multicolumn{3}{|c|}{ Official Estimates } & \multirow{2}{*}{$\begin{array}{l}\text { RP } \\
\text { Consistent } \\
1996 / 97\end{array}$} & \multicolumn{2}{|c|}{ PLEASe Estimates } \\
\hline Area & $1996 / 97$ & $2002 / 03$ & 2008/09 & & $2002 / 03$ & $2008 / 09$ \\
\hline National & 69.4 & 54.1 & 54.7 & 69.7 & 51.8 & 50.1 \\
\hline Urban & 62.0 & 51.5 & 49.6 & 61.8 & 49.2 & 45.6 \\
\hline Rural & 71.3 & 55.3 & 56.9 & 71.8 & 53.0 & 52.0 \\
\hline North & 66.3 & 55.3 & 46.5 & 67.3 & 51.6 & 41.7 \\
\hline Center & 73.8 & 45.5 & 59.7 & 74.1 & 46.9 & 56.2 \\
\hline South & 65.8 & 66.5 & 56.9 & 65.5 & 60.0 & 50.5 \\
\hline Niassa & 70.6 & 52.1 & 31.9 & 71.9 & 50.1 & 30.6 \\
\hline Cabo Delgado & 57.4 & 63.2 & 37.4 & 59.1 & 60.5 & 35.0 \\
\hline Nampula & 68.9 & 52.6 & 54.7 & 69.4 & 48.1 & 47.9 \\
\hline Zambézia & 68.1 & 44.6 & 70.5 & 67.6 & 45.2 & 67.6 \\
\hline Tete & 82.3 & 59.8 & 42.0 & 81.9 & 60.5 & 39.1 \\
\hline Manica & 62.6 & 43.6 & 55.1 & 62.4 & 46.7 & 50.5 \\
\hline Sofala & 87.9 & 36.1 & 58.0 & 87.8 & 38.7 & 53.3 \\
\hline Inhambane & 82.6 & 80.7 & 57.9 & 83.0 & 78.6 & 54.2 \\
\hline Gaza & 64.7 & 60.1 & 62.5 & 64.8 & 54.8 & 58.1 \\
\hline Maputo Province & 65.6 & 69.3 & 67.5 & 65.6 & 59.4 & 56.8 \\
\hline Maputo City & 47.8 & 53.6 & 36.2 & 47.1 & 43.1 & 29.2 \\
\hline
\end{tabular}

Sources: MPF/DNPO (1998, 2004); MPD/DNEAP (2010); and authors' calculation.

Moving to the 2002/03 survey, a number of the major logistical challenges facing the survey team had been relieved compared with 1996/97. A census in 1997 provided a sample frame. ${ }^{3}$ While infrastructure remained poor in an absolute sense, substantial efforts had been made to improve roads and other key infrastructure. Landmines remained a threat, but demining activities had been successfully ongoing for years with literally millions of landmines removed and remaining areas with landmines largely cordoned off. Climatic conditions were generally favourable both for crop production and for the conduct of the survey. Problems with nonstandard units were mitigated by providing enumerator teams with portable scales such that a local unit (e.g., a can) could be converted to grams, litres, or some other standard measure.

The team engaged in the analysis of the 2002/03 survey maintained the essential structure of the analysis from 1996/97. As noted, the 1996/97 set a high standard for comprehensiveness and quality, especially in light of the difficulties encountered by enumerators in the field. Hence, the choice to maintain the essential structure followed logically.

Maintaining exact coherence was difficult, however. Consistent with standard practice at the time, the capability to reproduce the 1996/97 analysis from the raw data had not been preserved.

\footnotetext{
3 The 1997 census adopted a broader definition of urban than had been applied to IAF96. In particular, IAF96 defined 20 per cent of the population as urban while the 1997 census defined about 30 per cent of the population as urban.
} 
A series of coding files had been used to generate a series of databases; however, the exact mapping between coding files and databases had been only loosely documented. To compound matters, analysis took place in two separate computer languages: SPSS and STATA. Finally, the data itself underwent a prolonged cleaning process that continued through the process of analysis.

The inability to reproduce the 1996/97 analysis implied that, for 2002/03, the series of choices necessary to, for example, produce the nominal consumption aggregate or to estimate prices were made frequently on the basis of recall by team members from the first assessment. To prevent recurrence of this situation, the second assessment constructed a continuous code stream that began with the raw data files as obtained from the statistics service and progressed through to final results. This guaranteed the ability to reproduce results and provided complete documentation of all decisions. This code also turned out to be an antecedent of PLEASe.

For 2002/03, a series of additional choices were required. The simplest approach to estimating poverty would have been to use the bundles derived in 1996/97 and price them in 2002/03 (implicitly assuming an elasticity of substitution in consumption of zero). This approach yielded a decline in poverty to about 63 per cent (MPF/DNPO 2004). However, an analysis of the poverty rate that would have prevailed assuming a Cobb-Douglas utility function (assuming an elasticity of substitution equal to one) yielded a poverty rate of about 52 per cent (Arndt and Simler 2010). This analysis implied that substitution across foods in consumption was potentially important given observed changes in relative prices. Hence, the decision was made to re-estimate the bundles.

Consistent with best practice at the time, the team charged with the second assessment adopted a version of the iterative approach to estimating poverty lines discussed in Ravallion and Bidani (1994). Once again, consistency of this approach with the one applied in 1996/97 was achieved mainly via recall. In addition, analysis conducted after the publication of the first assessment indicated revealed preference violations for some of the final bundles derived in 1996/97. Violations were also detected for many of the initial bundles emanating from the iterative approach used in 2002/03. As a result, the approach for estimating utility consistent poverty lines discussed in Arndt and Simler (2010) was applied to 2002/03 food bundles.

Spatial utility consistency was only imposed on estimated poverty lines for 2002/03 but not retroactively to the bundles derived in 1996/97. As shown in Table 1, application of spatial utility consistency to 1996/97 would have changed the published poverty estimates for that survey year. For the Mozambican government and statistics service, any change in existing official poverty estimates was unacceptable. The decision to leave 1996/97 estimates alone had implications for the application of temporal conditions. Specifically, the temporal conditions applied in 2002/03 were made relative to bundles from 1996/97 that were themselves, revealed preference inconsistent (though not dramatically so).

In addition, the first assessment team had encountered serious problems in estimating food bundles in the urban zone of the province of Maputo, which contains the capital city. These bundles were also estimated to fail spatial revealed preference conditions. The complexities of Maputo were also evident in 2002/03 with high quality bundles emerging from the iterative procedure.

In the end, for 2002/03, the fixed bundle approach was imposed on Maputo (three spatial domains) by bringing forward the 1996/97 bundles and pricing them in 2002/03. This choice was pragmatic at the time given the demand for published results. Nevertheless, it did set the poverty lines, hence rates in Maputo to their maximum level consistent with temporal revealed 
preferences and ignored the spatial failure of revealed preference conditions (too high quality) of these bundles in 1996/97. The bundles for the remaining 10 spatial domains were estimated using an iterative procedure similar to the one described in Ravallion and Bidani (1994). Spatial and temporal revealed preference conditions were applied to these 10 spatial domains.

Results for 2002/03 indicated a substantial decline in poverty. At the national level, the poverty rate declined by 15 percentage points to about 54 per cent (see Table 1). These results were attributed to a return to a more normal living standard relative to the very low standards prevailing in the immediate post civil war period, climatic conditions reasonably favourable to agricultural production, and positive underlying development dynamics. The relative weights across these factors are essentially impossible to ascertain.

Turning to 2008/09, the survey was conducted on a sample derived from a new population census carried out in 2007 . For this third assessment, the analytical team had the possibility to begin from the code stream developed for the second assessment in 2002/03. This constituted a considerable advantage (similar to PLEASe). As care had been exercised to maintain comparability of questionnaires across all the surveys, the mechanics of the analysis were simplified, and the approach applied in 2008/09 was essentially identical to the one applied in $2002 / 03$. This included continued special treatment of Maputo with respect to revealed preference conditions and the imposition of utility consistency. ${ }^{4}$

With the advantage of an established approach, more detailed analysis and crosschecking became possible. The third assessment contains a large array of cross checks and sensitivity analyses using data from both the 2008/09 budget survey and across alternative sources of information (MPD/DNEAP 2010). For example, the rate of price inflation implied by the poverty lines over the period 2002/03 to 2008/09 was compared with the rates implied by price data from the agricultural market information system and detailed consumer price index data. In addition, a macroeconomic analysis was undertaken in order to establish broad consistency with national accounts (Arndt et al. 2012, 2016d).

For the third assessment, the potential for undercounting of consumption, essentially exclusively in urban zones and mainly in the South, also came to the fore (see section 10.6 of MPD/DNEAP 2010). This issue had been flagged in 2002/03 but not analysed in detail in order to produce the 2002/03 report in a timely fashion. In both 2002/03 and 2008/09, median household consumption of calories in urban zones, mainly in the South, was implausibly low.

While the official data remained the source for official poverty rates, a large variety of approaches were used to impute potential missing consumption in 2002/03 and in 2008/09 (section 10.6, MPD/DNEAP 2010) as a form of sensitivity analysis. These and other analyses confirmed stagnation in poverty rates at the national level. Urban rates declined while rural rates increased. These essential conclusions pertained regardless of the calorie correction procedure employed (MPD/DNEAP 2010). ${ }^{5}$ The combination of the global food and fuel price shocks of

\footnotetext{
${ }^{4}$ Specifically, revealed preference conditions (both spatial and temporal) were applied within the three Maputo domains and within the ten remaining domains outside of Maputo. But, as with all earlier assessments, higher quality bundles (e.g., revealed preference failures) for the three Maputo domains relative to the ten non-Maputo domains were permitted.

${ }^{5}$ Calorie corrections do substantially influence the regional poverty profile with urban areas exhibiting lower poverty rates, particularly in the South. This issue is discussed in detail in MPD/DNEAP (2010). Nevertheless, in order to facilitate comparison with official estimates, all subsequent analysis is conducted using the official data.
} 
2008 and a weather-induced decline in agricultural production, particularly in the Central provinces, drove the results (Arndt et al. 2012, 2016a).

\section{PLEASe estimates}

As shown in Table 1, the PLEASe estimates are qualitatively very similar to the official results. At the national level, a substantial fall in poverty occurred between 1996/97 and 2002/03. For both approaches, this decline was led by rural zones though poverty rates also fell substantially in urban zones. Between 2002/03 and 2008/09, the rate of poverty reduction levelled off with both the official data and the estimates based on PLEASe exhibiting an essential stagnation in poverty rates at the national level. The point estimates for the official data suggest a slight rise while the estimates from PLEASe suggest a small decline in national poverty rates. In neither case is there a statistically significant change in poverty at the national level (for the procedure for computing standard errors on poverty rates, see Simler and Arndt 2007). For rural and urban zones, the approaches point to a mixture of relatively small changes in poverty, though the urban decline is more pronounced in the estimates based on the PLEASe code.

At the provincial level, poverty levels and trends are also quite similar. Table 2 shows correlations between the official estimates and PLEASe. For both poverty levels and poverty trends, correlations of at least 0.93 and normally much more are obtained for all possible comparisons when calculated across provinces. PLEASe does result in lower estimates of poverty rates in Maputo Province and Maputo City with a shift from a rise in poverty point estimate between 1996/97 and 2002/03 to a decline. Neither the rise (official) nor the decline (PLEASe) in Maputo between 1996/97 and 2002/03 is statistically significant. The measured decline is more consistent with other analyses (e.g., Arndt et al. 2016c).

While the spatial poverty profile is remarkably similar between official and PLEASe estimates as indicated by the correlation analysis shown in Table 2, the PLEASe approach generates somewhat lower estimates of poverty in both years, which cumulate to a 4.6 percentage point reduction in the national poverty rate relative to the official estimates in 2008/09. This cumulative differential is distributed roughly equally between rural and urban zones.

As noted, the code streams applied to produce the official Mozambican poverty results are antecedents to PLEASe. As such, the official and PLEASe approaches are quite similar, particularly with respect to broad strategic choices. Specifically, both approaches adopt a 'cost of basic needs' approach. Both preserve the division of the country into the 13 spatial domains developed in 1996/97. Both employ an iterative approach to arriving at initial poverty lines from the 2002/03 and 2008/09 surveys. These poverty lines are then adjusted to conform to revealed preference conditions using the basic approach applied by Arndt and Simler (2010). The main differences between the official approach and the PLEASe estimates presented in Table 1 stem from the operational application of this basic approach. These differences are as follows.

As noted, in 1996/97, code was not made available to reproduce the full analysis. Hence, for $1996 / 97$, the only change is to impose revealed preference consistency on the official bundles from 1996/97. This results in mild changes to the estimated poverty rates for 1996/97 as shown in Table 1.

Turning to 2002/03 and 2008/09, the main differences in the methods underlying the official numbers and those underlying the results presented under the PLEASe columns in Table 1 are as follows (with the text referring to the official approach as the baseline). First, the iterative estimation procedure for determining initial poverty lines is modified to account more 
completely for spatial variations in the cost of living in the first iteration. Specifically, in the official approach, the iterative procedure is applied nationally with an initial spatial price index determined in a preliminary round of poverty estimations and an initial cut-point identifying relatively poor households that is set at 60 per cent. In PLEASe, the iterative procedure is applied by spatial domain with both the initial spatial price index and initial cut-points values taken from the preceding survey. Second, food items lacking corresponding prices or calories, such as meals away from home, are dropped prior to food basket estimations as opposed to dropping items after estimating the basket. Third, for consistency between surveys, the basket employed for calculating the 2002/03 temporal index within the survey year is expanded. Fourth, an improved procedure is employed for estimating prices of items with few observations in the spatial revealed preference calculations. Finally, spatial revealed preference conditions are imposed nationally with no special treatment for Maputo.

In $2002 / 03$, these changes result in an estimated national poverty rate prior to the imposition of revealed preference conditions of about 46 per cent in PLEASe versus about 48 per cent using the official methodology (derived principally from the first three changes). The procedure for imposing spatial and temporal revealed preference conditions then drives up the national poverty rate by essentially the same amount (about 6 percentage points) in both the official and PLEASe approaches.

The main driver of this increase in poverty rates relative to the value derived directly from the iterative procedure, in both instances, is a strong failure of revealed preference conditions in rural Nampula, which is the most populous province (MPF/DNPO 2004). As noted, the poverty profile does shift. The inclusion of the Maputo spatial domains in the correction procedure in PLEASe tends strongly to lower the quality of the bundles in Maputo resulting in lower poverty rates in Maputo Province and City. The poverty rate in Maputo is about 10 percentage points lower in Maputo in PLEASe versus the official numbers, almost entirely as a consequence of the imposition of revealed preference conditions on the three Maputo spatial domains.

In terms of changes from the iterative procedure poverty rates at the national level, the lowering of rates in Maputo in PLEASe is offset by slightly greater increases in rural poverty, which is also a consequence of the inclusion of Maputo domains in the revealed preference adjustment. As noted above, the net impact of the inclusion of Maputo domains on the increase in the national poverty rate is essentially the same between the official and PLEASe approaches, at about 6 percentage points. Hence, the approximately two-point difference in the poverty rate obtained from the iterative procedure persists in the post-adjustment numbers with the official rate at about 54 per cent and the new PLEASe estimate at about 52.

Moving on to $2008 / 09$, the poverty rates obtained prior to the imposition of revealed preference conditions are, in this case, very similar at about 53.5 per cent of the population for both the official (53.6) and PLEASe estimates (53.3). In addition, when only spatial revealed preference conditions are applied to the PLEASe estimates, the resulting national poverty rate is 54.9 per cent, which is very close to the official national estimate. However, the somewhat lower poverty lines developed for 2002/03 are now also imposed as temporal conditions on the estimation of the 2008/09 poverty lines. The imposition of these temporal conditions shifts the national poverty rate downward by about 5 percentage points to the level of 50.1 shown in Table 1 . Therefore, the principal effect driving the difference in the national poverty rate between the official and PLEASe estimates in 2008/09 is the lower welfare anchor (i.e., somewhat lower poverty lines) derived from the 2002/03 estimates via the temporal revealed preference conditions. 
To recap, the default iterative procedure employed in PLEASe results in a national poverty rate in 2002/03, derived from the iterative procedure, that is a bit more than 2 percentage points lower than the value derived from the iterative procedure employed for the official analysis (the first three differences in methods discussed above). After correction for revealed preference violations, the level of poverty rises in both cases and the two-point differential between the official national poverty estimate (54.1) and PLEASe (51.8) essentially persists.

The somewhat lower poverty rates derived from PLEASe in 2002/03 correspond to somewhat lower poverty lines (note that nominal consumption estimates for each household are the same in the official and PLEASe approaches). These somewhat lower poverty lines are then employed as temporal conditions in 2008/09. These temporal conditions are binding and hold national poverty rates to lower levels. In other words, the bundles emerging from the PLEASe iterative procedure in 2008/09 are of somewhat higher quality than the final bundles from 2002/03. While the official estimates produce a slight rise in poverty at the national level (0.6 points) between 2002/03 and 2008/09, the PLEASe estimates produce a small decline (-1.7 points).

It is worthwhile to emphasize that the differentials in poverty rates discussed above are not large relative to standard deviations for national poverty rates, which are estimated at about 1.7 or 1.8 percentage points (Simler and Arndt 2007; MPD/DNEAP 2010), and well within a confidence interval of about two standard deviations. Nevertheless, the two differentials do accumulate resulting in a poverty rate in 2008/09 for PLEASe that is 4.6 percentage points below the official estimate for the same year.

As the correlations in Table 2 illustrate, the poverty profiles are very similar between the two sets of estimates. As expected, imposition of revealed preference conditions on the domains in Maputo reduce estimated poverty rates in Maputo Province and City in PLEASe relative to the official numbers. Once the national level difference of 4.6 percentage points is accounted for in 2008/09, differences in provincial poverty rates between the official estimates and PLEASe amount to much less than one standard deviation for all provinces, excepting Maputo, and for rural and urban domains.

\footnotetext{
${ }^{6}$ Whether this differential is statistically significant is complex due to dependence between the 2002/03 and 2008/09 final rates. This dependence comes about through the temporal revealed preference conditions. Under an assumption of independence, the standard deviation of the difference in national poverty rates between 2002/03 and 2008/09 is about 2.45 (MPD/DNEAP 2010). Accounting for dependence would likely reduce this standard error meaning that the difference between the official 2002/03 national estimate and the PLEASe 2008/09 estimate would likely be near the edge of the confidence interval.
} 
Table 2: Correlations in levels and trends between official and PLEASe estimates

\begin{tabular}{lll}
\hline & \multicolumn{2}{l}{ Provinces } \\
\cline { 2 - 3 } & Levels & Changes \\
\hline $1996 / 97$ & 0.998 & - \\
$2002 / 03$ & 0.933 & 0.978 \\
$2008 / 09$ & 0.981 & 0.987 \\
$1996 / 97-2008 / 09$ & - & 0.988 \\
\hline
\end{tabular}

Note: Correlations are calculated across the ten provinces plus Maputo City as shown in Table 1.

Sources: MPF/DNPO (1998, 2004); MPD/DNEAP (2010); and authors' calculation.

\section{$4 \quad$ Discussion and conclusions}

Poverty analysis is conducted mainly for the purpose of making robust comparisons. Often, comparisons through time generate the greatest level of interest. These comparisons respond to the key question: Are living standards improving/stagnating/deteriorating through time? As poverty estimates are sensitive to the methods employed for deriving them, there is great value in applying fully consistent methods. At the same time, data collection approaches, the practice of poverty analysis, and the circumstances under which the analysis is conducted, evolve through time. While considered the most appropriate at the time, choices made in past analyses may not correspond to current best practice and/or may not be as suitable to current circumstances. ${ }^{7}$ There is, as a result, a natural tension between maintaining consistency, and hence comparability, with previous analyses and the desire to obtain the best possible estimates of welfare given the state of knowledge of practice of poverty analysis as well as current circumstances.

To our knowledge, there is no established procedure for coping with this tension even though it is appearing with increasing frequency. For example, in Tanzania, changes to survey design and methodological approach were introduced with the 2011/12 survey (World Bank 2015; Arndt et al. 2016a) creating issues of comparability with earlier work. In order to attempt to develop comparable numbers with the preceding survey conducted in 2007 , revisions were imposed on measured consumption and associated poverty lines. As a consequence of these revisions, estimated consumption per adult equivalent in 2007 rose by almost one-third with a similar increase imposed on the poverty lines. ${ }^{8}$ The end result was only a minor shift in measured poverty at the national level (World Bank 2015).

In assessing long run poverty trends for Tanzania, Arndt et al. (2016a) present two poverty estimates for 2007, one of which is meant to be comparable with earlier surveys in 2001 and 1992, and the other comparable with the subsequent survey in 2011/12. The recent poverty assessment for Tanzania (World Bank 2015) copes with the issue principally by refraining from mentioning measured poverty rates calculated in 2001 and in 1992, ostensibly due to comparability issues.

\footnotetext{
${ }^{7}$ Changes in data collection approaches likely present even greater conundrums (Deaton and Kozel 2005).

${ }^{8}$ This is a very large increase. According to World Bank, the increases are partly due to inclusion of education, health, and communication expenditures, which were previously excluded, and 'partly due to a different way of drawing on the diary and recall data for nonfood spending' (2015: 2). The magnitude of these shifts indicates that one can really only hope to detect gross trends in consumption poverty. Arndt et al. (2016b) provide further analysis for Tanzania.
} 
For this paper, we present new estimates for all three survey years with available data for Mozambique though, as in Tanzania, the focus is on more recent survey years. We find that the essential conclusions of the three poverty assessments undertaken to date are maintained. In particular, poverty rates were uniformly high in 1996/97. Poverty rates reduced dramatically between 1996/97 and 2002/03 with particularly strong decreases registered in rural areas. Between 2002/03 and 2008/09, poverty at the national level stagnated with less favourable outcomes in rural compared with urban zones.

The estimates obtained via the default PLEASe software code indicate a larger decline in consumption poverty between 1996/97 and 2002/03 than the official estimate. Between 2002/03 and 2008/09, point estimates from PLEASe register a small decline as opposed to the very small increase in the official numbers. None of these differences is even close to being significant statistically. Nevertheless, as both differentials are in the same direction, the cumulative effect results in an estimated poverty rate at the national level derived from PLEASe that is 4.6 percentage points below the official estimate for 2008/09. Regional poverty profiles are qualitatively similar between the two sets of estimates with lower rates registered in the South, particularly Maputo province.

The results illustrate the value of the application of a consistent approach with this need for consistency in approach applying to essentially all calculations rather than only the broad strategies (e.g., cost of basic needs) employed. In updating methods and survey approaches over time, there appears to be no substitute for returning to the original data and re-estimating previous surveys in order to maintain consistency through time.

\section{References}

Arndt, C., H.T. Jensen, and F. Tarp (2000). 'Stabilization and structural adjustment in Mozambique'. Journal of International Development, 12: 299-323.

Arndt, C., and K. Simler (2010). 'Estimating utility-consistent poverty lines with applications to Egypt and Mozambique'. Economic Development and Cultural Change, 58(3): 449-74.

Arndt, C., M.A. Hussain, E.S. Jones, V. Nhate, F. Tarp, and J. Thurlow (2012). 'Explaining the evolution of poverty: the case of Mozambique'. American Journal of Agricultural Economics, 94(4): 854-72.

Arndt, C., L. Demery, A. McKay, and F. Tarp (2016a). 'Growth and poverty reduction in Tanzania'. In C. Arndt, A. McKay, and F. Tarp (eds), Growth and Poverty in Sub-Saharan Africa. Oxford: Oxford University Press.

Arndt, C., V. Leyaro, K. Mahrt, and F. Tarp (2016b). 'Growth and poverty: A pragmatic assessment and future prospects'. In C. Adam, P. Collier, and B. Ndulu (eds), Tanzania: The Path to Prosperity. Oxford: Oxford University Pres.

Arndt, C.M., A. Hussain, V. Salvucci, F. Tarp, and L.P. Østerdal (2016c). 'Poverty mapping based on first order dominance with an example from Mozambique'. Journal of International Development, 28: 3-21.

Arndt, C., E.S. Jones, and F. Tarp (2016d). 'Mozambique: off-track or temporarily sidelined?'. In C. Arndt, A. McKay, and F. Tarp (eds), Growth and Poverty in Sub-Saharan Africa. Oxford: Oxford University Press. 
Deaton, A., and V. Kozel (2005). 'Data and dogma: the great Indian poverty debate'. The World Bank Research Observer, 20.2: 177-99.

Ministry of Planning and Development/DNEAP (MPD/DNEAP) (2010). 'Poverty and wellbeing in Mozambique: Third national poverty assessment'. Maputo: Ministry of Planning and Development/DNEAP.

Ministry of Planning and Finance/DNPO (MPF/DNPO) (1998). 'Understanding poverty and wellbeing in Mozambique: The first national assessment, 1996-97'. Maputo: Ministry of Planning and Finance/DNPO.

Ministry of Planning and Finance/DNPO (MPF/DNPO) (2004). 'Poverty and wellbeing in Mozambique: Second national poverty assessment'. Maputo: Ministry of Planning and Finance/DNPO.

Ravallion, M. (2016). The Economics of Poverty: History, Measurement, and Policy. Oxford: Oxford University Press.

Ravallion, M., and B. Bidani (1994). 'How robust is a poverty profile?'. World Bank Economic Review, 8: 75-102.

Simler, K.R., and C. Arndt (2007). 'Poverty comparisons with endogenous absolute poverty lines'. Review of Income and Wealth, 53: 275-94.

World Bank (2015). Tanzania Mainland Poverty Assessment. Washington, DC: World Bank. 